\title{
Targeting Canine KIT Promoter by Candidate DNA G-Quadruplex Ligands $\$$
}

\author{
Eleonora Zorzan, Silvia Da Ros, Mery Giantin, Lara Zorro Shahidian, ${ }^{1}$ Giorgia Guerra, \\ Manlio Palumbo, Claudia Sissi, and Mauro Dacasto \\ Department of Comparative Biomedicine and Food Science, University of Padua, Agripolis Legnaro, Padua, Italy (E.Z., M.G., \\ L.Z.S., G.G., M.D.), and Department of Pharmaceutical and Pharmacological Sciences, University of Padua, Padua, Italy \\ (S.D.R., M.P., C.S.)
}

Received March 8, 2018; accepted September 26, 2018

\section{ABSTRACT}

G-quadruplexes (G4) are nucleic acid secondary structures frequently assumed by G-rich sequences located mostly at telomeres and proto-oncogenes promoters. Recently, we identified, in canine KIT (v-kit Hardy-Zuckerman 4 feline sarcoma viral oncogene homolog) promoter, two G-rich sequences able to fold into G4: d_kit1 and d_kit2_A16. In this study, an anthraquinone (AQ1) and an anthracene derivative (AN6), known to stabilize the G4 structures of the corresponding human h_kit1 and h_kit2, were tested on the canine G4 and in two canine mast cell tumor (MCT) cell lines ( $\mathrm{C} 2$ and $\mathrm{NI}-1)$ to verify their capability to down-regulate KIT expression. The cytotoxicity of AQ1 and AN6 was determined using the Alamar Blue test; also the constitutive expression of $K I T$ and other proto-oncogenes containing G4 structures in their promoter (BCL2, VEGF $\alpha$, VEGFR2, KRAS, and TERT) was assessed by quantitative real-time polymerase chain reaction
(qRT-PCR). Then the time- and dose-dependent effects of both ligands on target gene expression were assessed by qRT-PCR. All target genes were constitutively expressed up to 96 hours of culture. Both ligands decreased KIT mRNA levels and c-kit protein amount, and AN6 was comparatively fairly more effective. DNA interaction studies and a dualluciferase gene reporter assay performed on a noncancerous canine cell line (Madin-Darby Canine Kidney cells) proved that this down-regulation was the result of the interaction of AN6 with KIT proximal promoter. Interestingly, our results only partially overlap with those previously obtained in human cell lines, where AQ1 was found as the most effective compound. These preliminary data might suggest AN6 as a promising candidate for the selective targeting of canine KIT-dependent tumors.

\section{Introduction}

The G-quadruplex (G4) are tetrahelical structures formed by guanine-rich nucleic acid sequences. In these structural elements, four guanine residues are connected through Hoogsteen hydrogen bonds to constitute a G-quartet, and

This work was supported by grants from the University of Padua (CPDA114388, CPDA147272) [to M.D. and C.S.], E.Z., and S.D.R. were recipient of Ph.D. fellowships and 1-year postdoc grant fellowships from the University of Padua.

Preliminary results were previously presented at the following conferences: Sissi C, Da Ros S, Zorzan E, Palumbo M, Giantin M, Dacasto M (2015) G-rich sequences within proto-oncogene KIT promoter region as targets for anticancer therapy. 5th International Meeting on Quadruplex Nucleic Acids; 2015 May 26-28; Bordeaux, France; and Giantin M, Zorzan E, Da Ros S, Shahidian LZ, Palumbo M, Sissi C, Dacasto M (2015) Targeting canine c-KIT promoter by candidate DNA G-quadruplex ligand. Annual Congress of the European Society of Veterinary Oncology; 2015 May 28-30, Krakow, Poland.

${ }^{1}$ Current affiliation: Institute of Functional Epigenetics, Helmholtz Zentrum München, Neuherberg, Germany.

https://doi.org/10.1124/jpet.118.248997.

S This article has supplemental material available at jpet.aspetjournals.org. three or more quartets stacked one over the other form a G4 (Zhao et al., 2007; Lipps and Rhodes, 2009). Bioinformatics analysis identified around 400,000 putative G4-forming sequences in the human genome (Bidzinska et al., 2013), preferentially localized to telomeres and functional regions such as the transcription start site, the $5^{\prime}$-untranslated region, and the $5^{\prime}$ end of the first intron; however, they are depleted in coding regions (Huppert and Balasubramanian, 2007; Maizels and Gray, 2013; Rhodes and Lipps, 2015). Evidence suggests that G4 formation plays a role in cellular telomerase maintenance, DNA transcription, and RNA translation (Huppert and Balasubramanian, 2007; Bidzinska et al., 2013; Teng et al., 2017).

The sequence of these guanine-rich portions are generally highly conserved between different species, suggesting a selection pressure to retain such sequences at specific genomic sites (Lipps and Rhodes, 2009). This conservation is greatest among mammalian species, while it decreases in non-mammalian species and other organisms (Lipps and Rhodes, 2009). The presence of

ABBREVIATIONS: ANOVA, analysis of variance; BCL2, B-cell leukemia/lymphoma 2; CCZ1, vacuolar protein trafficking and biogenesis associated homolog; CGI-119, transmembrane BAX inhibitor motif containing 4; DMSO, dimethylsulfoxide; dsDNA, double-stranded DNA; G4, G-quadruplex; GAPDH, glyceraldehyde-3-phosphate dehydrogenase; ICG, internal control gene; KIT, v-kit Hardy-Zuckerman 4 feline sarcoma viral oncogene homolog; KRAS, Kirsten rat sarcoma viral oncogene homolog; MCT, mast cell tumor; MDCK, Madin-Darby Canine Kidney; MYC, v-myc avian myelocytomatosis viral oncogene homolog; qRT-PCR, quantitative real-time polymerase chain reaction; RQ, relative quantification; TERT, telomerase reverse transcriptase; TKI, tyrosine kinase inhibitor; TO, thiazole orange; VEGFA, vascular endothelial growth factor A. 
G4-forming sequences in genomes other than the human one has already been investigated, particularly in prokaryotes (Kang and Henderson, 2002; Rawal et al., 2006; Beaume et al., 2013; Kota et al., 2015) and warm-blooded animals such as the chicken, rat, mouse, dog, and zebrafish (Du et al., 2007; Zhao et al., 2007; Verma et al., 2008). In humans, the maximum frequency of putative G4-forming DNA sequences occurs in the gene transcriptional regulatory region, usually found between the -500 and +499 regions, and particularly in the 100 base pairs preceding the transcription starting site (Zhao et al., 2007).

Recently, three G4-forming structures_h_kit1, h_kit2, and kit*-were identified in the proximal promoter of the human proto-oncogene v-kit Hardy-Zuckerman 4 feline sarcoma viral oncogene homolog (KIT) (Rankin et al., 2005; Fernando et al., 2006; Raiber et al., 2012). KIT codes for a tyrosine kinase receptor (c-kit) implicated in cell survival, proliferation, and differentiation; furthermore, the occurrence of activating mutations or its overexpression can result in aberrant functions and oncogenic cellular transformation in cells such as interstitial cells of Cajal and myeloid cells (Balasubramanian et al., 2011).

The stabilization of human KIT G4 has been induced by using different classes of G4 ligands, such as trisubstituted isoalloxazines, bis-indole carboxamides, and benzo[a]phenoxazines; in all instances, a reduction of gene expression was derived (Bejugam et al., 2007; Dash et al., 2008; McLuckie et al., 2011). In a previous study, we selected and tested in different human neoplastic cell lines an anthraquinone and an anthracene derivative: $\mathrm{AQ} 1$ and AN6, respectively. Both compounds stabilized h_kit1 and h_kit2 and led to an inhibition of cell proliferation and KIT down-regulation, with AQ1 being more effective than AN6 (Zorzan et al., 2016).

Pet dogs spontaneously develop cancers that share many characteristics with those found in humans, including biochemical pathways known to be drivers in certain human malignancies; this offers to comparative oncologists the opportunity to target these mechanisms in dogs and allow an accurate preclinical assessment of novel therapeutics (Gardner et al., 2016).

In canines, cutaneous mast cell tumor (MCT) is the most common skin tumor, and KIT mutations cause a constitutive protein activation, resulting in uncontrolled mast cell proliferation (Gil da Costa, 2015). The advent of targeted therapy and particularly the use of tyrosine kinase inhibitors (TKIs) brought some therapeutic benefits to the approach to MCTs; however, the potential for drug-resistance phenomena and the need to choose the best anticancer drug according to KIT mutational profile represent common problems (London et al., 2009; Bonkobara, 2015).

Through sequencing work, we confirmed that canine $K I T$ promoter also presents two putative G4 sequences: d_kit1 and d_kit2. The former is highly conserved between humans and dogs, but the second is species specific and presents a further isoform named d_kit2_A16. Accordingly, h_kit1 and d_kit1 share the same structural properties, but some differences in terms of folding kinetic and population distribution were observed between h_kit2 and d_kit2 (Da Ros et al., 2014).

To validate the KIT proximal promoter of dogs as a pharmacologic target for the prevention of malignant cell proliferation, we compared the interaction of AQ1 and AN6 with the human and canine kit1 and kit2. Subsequently, we tested the two derivatives on two canine MCT cell lines
(C2 and NI-1) already used in TKI validation (Dubreuil et al., 2009; Hadzijusufovic et al., 2012; Halsey et al., 2014).

\section{Materials and Methods}

Ligands. AQ1 and AN6 were synthesized by Prof. G. Zagotto (University of Padua, Italy). Stock solutions were prepared as previously reported elsewhere (Zorzan et al., 2016).

Canine Cell Lines. Two canine MCT cell lines were used in the present study. The $\mathrm{C} 2$ cell line is a well-characterized canine MCT cell line expressing a mutated KIT genotype (48 bp internal tandem duplication in the juxtamembrane domain); this cell line is the most commonly used in in vitro studies on canine MCT and was kindly provided by Dr. P. Dubreuil (Centre de Recherche en Cancérologie de Marseille, France). The NI-1 cell line is a more recent canine MCT cell line, expressing a mutated $K I T$ genotype $(107 \mathrm{C}>\mathrm{T} ; 1187 \mathrm{~A}>\mathrm{G}$; ITD $^{1263-1275}$ ) and kindly provided by Prof. P. Valent (Medizinische Universität, Vienna, Austria) and Drs. Emir Hadzijusufovic and Michael Willmann (Veterinärmedizinische Universität, Vienna, Austria). This second cell line was essentially used for confirmatory studies.

The cells were cultured in RPMI 1640 medium supplemented with $10 \%$ fetal bovine serum, $2 \mathrm{mM}$ L-glutamine, $1 \mathrm{mM}$ sodium pyruvate, and 1\% penicillin/streptomycin (Gibco/Thermo Fisher Scientific, Grand Island, NY). The Madin-Darby Canine Kidney (MDCK) cell line was purchased from the European Collection of Cell Cultures (Salisbury, United Kingdom). Cells were cultured in Eagle's Minimum Essential Medium (EMEM) supplemented with $10 \%$ fetal bovine serum, $2 \mathrm{mM}$ L-glutamine, 1\% nonessential amino acids (Gibco/Thermo Fisher Scientific), and 1\% penicillin/streptomycin. Cell number and viability were checked by using the Trypan Blue dye exclusion test (Sigma-Aldrich, St. Louis, MO).

The cell cultures were screened routinely for Mycoplasma spp. contamination using the PCR Mycoplasma Test Kit (PromoKine, Heidelberg, Germany) as per the manufacturer's instructions. For all the experiments, cells were used in passages between 5 and 30 maximum.

Sequencing of KIT Proximal Promoter. C2 and NI-1 cells were used to amplify (polymerase chain reaction) and clone into TOPO TA vector the canine KIT proximal promoter (KF471023), according to Da Ros et al. (2014). The plasmid DNA from eight different colonies was sequenced.

Fluorometric Titration and Fluorescent Intercalator Displacement Assay. Fluorometric measurements were performed using an LS55 Luminescence Spectrometer equipped with a Haake DC 30 (power supply) and K20 (bath) to thermostat cell holder (PerkinElmer Life and Analytical Sciences, Waltham, MA). Spectra were acquired using a quartz cuvette with $10-\mathrm{mm}$ path length and the following parameters: emission range $520-680 \mathrm{~nm}$, excitation wavelength $501 \mathrm{~nm}$, scanning speed $120 \mathrm{~nm} / \mathrm{min}, 25^{\circ} \mathrm{C}$.

For the fluorescent intercalator displacement assay, a solution containing $0.62 \mu \mathrm{M}$ of target DNA and $1.24 \mu \mathrm{M}$ of thiazole orange (TO) was added with increasing concentrations of tested ligand in $10 \mathrm{mM}$ Tris, $50 \mathrm{mM} \mathrm{KCl}, \mathrm{pH}$ 7.4. Changes in fluorescence emission were recorded. The percentage of TO displacement was calculated as follows: TO displacement $=100-\left[\left(F / F_{0}\right) \times 100\right]$, where $F_{0}$ is the fluorescence before addition of the ligand, plotted as a function of compound concentration. From these plots the $\mathrm{EC}_{50}$ (half maximal effective concentration) was calculated. Each titration was repeated at least in triplicate.

Fluorescence Melting Studies. Fluorescence melting analyses were performed with Light Cycler 480 II (Roche Applied Science, Indianapolis, IN) by setting the excitation source at $488 \mathrm{~nm}$ and recording the fluorescence emission at $520 \mathrm{~nm}$. Before data acquisition, a solution containing $0.25 \mu \mathrm{M}$ DNA in $10 \mathrm{mM} \mathrm{LiOH}$, pH 7.5 $\left(\mathrm{H}_{3} \mathrm{PO}_{4}\right)$, with $50 \mathrm{mM} \mathrm{KCl}$ was loaded on each well of a 96 -well plate and then added with increasing concentrations of the tested ligand. Samples were first heated to $95^{\circ} \mathrm{C}$ at a rate of $0.1^{\circ} \mathrm{C} \mathrm{s}^{-1}$, maintained at $95^{\circ} \mathrm{C}$ for 5 minutes and then annealed by cooling to $30^{\circ} \mathrm{C}$ at a rate of $0.1^{\circ} \mathrm{C} \mathrm{s}^{-1}$. Subsequently, samples were maintained at $30^{\circ} \mathrm{C}$ for 
5 minutes before being slowly heated to $95^{\circ} \mathrm{C}\left(1^{\circ} \mathrm{C} \mathrm{min}{ }^{-1}\right)$ and annealed at a rate of $1^{\circ} \mathrm{C} \mathrm{min}-1$.

For the analyses with double strands oligonucleotides, the two complementary strands were previously annealed $\mathrm{ON}$ in $10 \mathrm{mM}$ $\mathrm{LiOH}, \mathrm{pH} 7.5$, with $\mathrm{H}_{3} \mathrm{PO}_{4}$. The samples then were slowly heated to $95^{\circ} \mathrm{C}\left(1^{\circ} \mathrm{C} \mathrm{min}{ }^{-1}\right)$ and annealed at a rate of $1^{\circ} \mathrm{C} \min ^{-1}$.

For all analyses, recordings were taken during both the melting and annealing steps to check for hysteresis. Melting temperatures were determined from the first derivatives of the melting profiles using the Roche LightCycler software. Each curve was repeated at least three times and errors were $\pm 0.4^{\circ} \mathrm{C}$.

Polymerase Stop Assay. The polymerase stop assay was performed using a primer (d[TA 2 TACGACTCACTATAG]) previously labeled at the $5^{\prime}$-terminal with ${ }^{32} \mathrm{P}$. Template strands were designed to contain the target sequences (here named $\mathrm{X}$ ) at a conserved position: d[TC ${ }_{2} \mathrm{~A}_{2}$ CTATGTATAC(X)ACATATCGATGA $\mathrm{T}_{2}$ GCTATAGTGAGTCG$\left.\mathrm{TAT}_{2} \mathrm{~A}\right]$. For the annealing phase, a solution of 2:1 labeled primer/

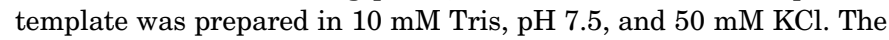
mixture was kept for 5 minutes at $95^{\circ} \mathrm{C}$ and then left to slowly cool down at room temperature.

For the primer extension step, the previous solution was added of 2.5 U Taq DNA Polymerase (Thermo Fisher Scientific, Waltham, MA), increasing ligand concentrations $(0.1-10 \mu \mathrm{M})$ as well as $\mathrm{MgCl}_{2}(3 \mathrm{mM})$ and dNTPs $(100 \mu \mathrm{M})$. The resulting mixture was kept at $55^{\circ} \mathrm{C}$ for 30 minutes, cooled in ice, dried, and finally solubilized with $5 \mu \mathrm{l}$ of loading buffer ( $80 \%$ formamide in water with $1 \%$ bromophenol blue and xylene cyanol). Before loading the gel, samples were put in boiling water for 5 minutes and then directly on ice. The reaction products were resolved on a $20 \%$ polyacrylamide gel (acrylamide/bisacrylamide 19:1) with $7 \mathrm{M}$ urea in $1 \mathrm{X}$ TBE buffer (89 mM Tris base, $89 \mathrm{mM}$ boric acid, $20 \mathrm{mM} \mathrm{Na}_{2}$ EDTA). At the end of the electrophoretic run, the gel was exposed overnight on a storage phosphor screen (Amersham Pharmacia Biotech Italia, Milan, Italy) and finally scanned with a Storm 840 (Amersham Pharmacia Biotech Italia).

G4 Ligands Cytotoxicity. The C2 and NI-1 cells were seeded in 96 -wells plates at a concentration of $2 \times 10^{4}$ cells per well and treated with AQ1 and AN6 at concentrations between 0.01 and $10.00 \mu \mathrm{M}$. Additional wells either exposed to the dimethylsulfoxide vehicle (DMSO, 0.1\% final concentration) or containing the medium only were included in each experiment as well.
After 72 hours of exposure, the cytotoxicity of the G4 ligands was measured by adding to each well $20 \mu \mathrm{l}$ of CellTiter-Blue Cell Viability Assay solution (Alamar Blue; Promega, Madison, WI) and measuring the fluorescence at $560 \mathrm{~nm}$ (excitation wavelength) and $590 \mathrm{~nm}$ (emission wavelength) by using a VICTORX4 Multilabel Plate Reader (PerkinElmer, Waltham, MA). Three separate experiments were performed, and each concentration was tested six times.

Time-Dependent Constitutive Expression of Target Genes. The constitutive mRNA levels of six genes containing putative G4 structures in their promoter were measured in C2 and NI-1 cells seeded onto six-well plates at a final concentration of $6 \times 10^{5}$ cells/well and were collected after $6,24,48,72$, and 96 hours $\left(\mathrm{T}_{6}, \mathrm{~T}_{24}, \mathrm{~T}_{48}, \mathrm{~T}_{72}\right.$, $\mathrm{T}_{96}$, respectively). The cell pellets were washed once with phosphatebuffered saline $1 \mathrm{X}$ containing $0.02 \%$ EDTA, then they were resuspended in $0.5 \mathrm{ml}$ of TRIzol reagent (Thermo Fisher Scientific). Total RNA extraction, its qualitative and quantitative evaluation, and the reverse transcription into cDNA were performed according to the methods of Zorzan et al. (2016).

The full list of primers used for qRT-PCR analysis is reported in Table 1 . The candidate genes were KIT, myc avian myelocytomatosis viral oncogene homolog $(M Y C)$, vascular endothelial growth factor A (VEGFA), Kirsten rat sarcoma viral oncogene homolog (KRAS), B-cell leukemia/lymphoma 2 (BCL2), and telomerase reverse transcriptase (TERT). Primer3 software (http://primer3.ut.ee/) was used to design primers. The specificity of each gene assay was evaluated in silico by means of the BLAST tool and experimentally by using the Power SYBR Green I (Thermo Fisher Scientific) amplification and melting curve analysis.

The qRT-PCR reactions were performed in a LightCycler 480 Instrument (Roche Applied Science) using 0.83 ng of C2 cells cDNA or $2.5 \mathrm{ng}$ of NI-1 cells cDNA (in $10 \mu \mathrm{l}$ final volume) and standard qRT-PCR conditions $\left(95^{\circ} \mathrm{C}\right.$ for 10 minutes; 45 cycles at $95^{\circ} \mathrm{C}$ for 10 seconds and at $60^{\circ} \mathrm{C}$ for 30 seconds; $40^{\circ} \mathrm{C}$ for 30 seconds). The calibration curves were made using 3 -fold serial dilutions of a cDNA pool, and the values of slope, efficiency (E), and dynamic range obtained with both cell lines are reported in Supplemental Table 1. Only qRT-PCR assays with efficiency between $90 \%$ and $110 \%$ were considered acceptable. The obtained qRT-PCR data were analyzed using LightCycler480 1.5.0 software (Roche Applied Science) and the

TABLE 1

Primers and probes used for qRT-PCR analyses

\begin{tabular}{|c|c|c|c|}
\hline Gene & Sequence & Source & UPL Probe \\
\hline$A T P 5 \beta$ & $\begin{array}{l}\text { F: TCTGAAGGAGACCATCAAAGG } \\
\text { R: AGAAGGCCTGTTCTGGAAGAT }\end{array}$ & Giantin et al. (2014) & $\# 120$ \\
\hline$B C L 2$ & $\begin{array}{c}\text { F : ACAACGGAGGCTGGGAATG } \\
\text { R: CCTTCAGAGACAGCCAGGAGAA }\end{array}$ & Designed ex novo & $\# 110$ \\
\hline$C C Z 1$ & $\begin{aligned} F: & \text { TGAAGCACTGCATTTAATTGTTTAT } \\
& \mathrm{R}: \text { CTTCGGCAAAAATCCAATGT }\end{aligned}$ & Giantin et al. (2016) & $\# 148$ \\
\hline CGI-119 & $\begin{array}{c}\text { F: tctacaatctaagagagatttcagcaa } \\
\text { R: ttcctgacaagcacaaatcc }\end{array}$ & Aresu et al. (2011) & $\# 15$ \\
\hline GOLGA1 & $\begin{array}{l}\mathrm{F}: \text { ggtggctcaggaagttcaga } \\
\mathrm{R}: \text { tatacggctgctctcctggt }\end{array}$ & Aresu et al. (2011) & $\# 149$ \\
\hline KIT & $\begin{aligned} \mathrm{F}: & \text { CCTTGGAAGTAGTAGATAAAGGATTCA } \\
& \mathrm{R}: \text { CAGATCCACATTCTGTCCATCA }\end{aligned}$ & Designed ex novo & $\# 60$ \\
\hline$K R A S$ & $\begin{array}{c}\text { F: TGTGGTAGTTGGAGCTGGTG } \\
\text { R: TCCCTCATTGCACTGTACTCCT }\end{array}$ & Designed ex novo & $\# 62$ \\
\hline$M Y C$ & $\begin{array}{c}\text { F : GCTGCACGAGGAGACACC } \\
\text { R: tcaatttcttcttcgtcctcttg }\end{array}$ & Designed ex novo & $\# 77$ \\
\hline$T E R T$ & $\begin{array}{l}\mathrm{F}: \text { tgacgtggaagatgaaggtg } \\
\mathrm{R}: \text { ctctctccgacggtgttc }\end{array}$ & Designed ex novo & $\# 128$ \\
\hline VEGFA & $\begin{array}{c}\text { F: CGTGCCCACTGAGGAGTT } \\
\text { R: GCCTTGATGAGGTTTGATCC }\end{array}$ & Giantin et al. (2012) & $\# 9$ \\
\hline
\end{tabular}

ATP5 $\beta$, ATP synthase, $\mathrm{H}^{+}$transporting, mitochondrial $\mathrm{F} 1$ complex, beta polypeptide; BCL2, B-cell leukemia/lymphoma 2; CCZ1, vacuolar protein trafficking and biogenesis associated homolog; CGI-119, transmembrane BAX inhibitor motif containing 4; GOLGA1, Golgin A1; KIT, v-kit Hardy-Zuckerman 4 feline sarcoma viral oncogene homolog; KRAS, Kirsten rat sarcoma viral oncogene homolog; $M Y C$, v-myc avian myelocytomatosis viral oncogene homolog; TERT, telomerase reverse transcriptase; UPL, Universal Probe Library; VEGFA, vascular endothelial growth factor A. 
second derivative method. The relative quantification (RQ) of target gene mRNA levels was achieved by using the $\Delta \Delta \mathrm{Ct}$ method (Livak and Schmittgen, 2001).

Four internal control genes (ICGs) were selected: the ATP synthase, $\mathrm{H}^{+}$transporting, mitochondrial $\mathrm{F} 1$ complex, beta polypeptide (ATP5 $\beta$ ), the Golgin A1 (GOLGA1), the transmembrane BAX inhibitor motif containing 4 (CGI-119), and the vacuolar protein trafficking and biogenesis associated homolog (CCZ1). These ICGs were amplified in all samples, but only those whose mRNA levels were not statistically significantly modulated by the adopted experimental conditions were used for the RQ of target genes. Moreover, a cDNA pool was used as calibrator. The experiments were performed in triplicate, with each one consisting of two biologic replicates.

Transcriptional Effects of G4 Ligands on Target Genes. The cells were incubated with the vehicle alone (DMSO, $0.1 \%$ final concentration) and two subcytotoxic doses of G4 ligands, at one-third and twothirds of their half maximal inhibitory concentration $\left(\mathrm{IC}_{50}\right)$. Specifically, the $\mathrm{C} 2$ cells were treated with 0.5 and $1 \mu \mathrm{M}$ of $\mathrm{AQ} 1$ and 2 and $4 \mu \mathrm{M}$ of AN6 (final concentrations); the NI-1 cells were treated with 0.08 and $0.16 \mu \mathrm{M}$ of AQ1 and 0.7 and $1.4 \mu \mathrm{M}$ of AN6 (final concentrations).

After 6, 12, and 24 hours of incubation, cell pellets were collected as described earlier. The expression of the whole set of candidate ICGs was checked within every experimental condition, and the choice of the most suitable ICG for normalization was cell line and ligand dependent. A cDNA pool was used as calibrator. Each experiment was performed in triplicate, with each one consisting of three biologic replicates.

Confirmatory Post-translational Effects of G4 Ligands. On the first day of the experiment, C2 and NI-1 cells $\left(5.4 \times 10^{6}\right.$ cells/well $)$ were seeded in Petri dishes. The C2 cells were treated for 24 hours with AQ1 $(1.5 \mu \mathrm{M})$, AN6 $(4 \mu \mathrm{M})$, or DMSO $(0.1 \%)$; the NI-1 cells were treated with $0.23 \mu \mathrm{M}$ of AQ1, $1.4 \mu \mathrm{M}$ of AN6, or $0.1 \%$ of DMSO. After washing with phosphate-buffered saline $1 \mathrm{X}$ with $0.02 \%$ EDTA, the cell pellets were resuspended in radioimmunoprecipitation assay buffer (50 mM Tris-HCl, $\mathrm{pH} 7.4,1 \%$ Triton X-100, 0.5\% Na-deoxycholate, $0.1 \%$ SDS, $150 \mathrm{mM} \mathrm{NaCl}, 2 \mathrm{mM}$ EDTA, $0.2 \mathrm{mM}$ sodium orthovanadate, $1 \%$ protease inhibitor cocktail; Sigma-Aldrich), incubated for 30 minutes on an ice bed, and centrifuged for 10 minutes at high speed.

Proteins were separated in 4\%-12\% NuPAGE Novex Bis-Tris Gels (Thermo Fisher Scientific) by using the XCell SureLock Mini-Cell electrophoresis system (Thermo Fisher Scientific), and transferred onto nitrocellulose filters through the iBlot Dry Blotting System (Thermo Fisher Scientific). On each gel, one prestained molecular marker (Thermo Scientific PageRuler Plus Prestained Protein Ladder, Thermo Fisher Scientific), an unstained molecular marker (MagicMark XP Western Protein Standard, Thermo Fisher Scientific), and a c-kit positive control (TF1 cells stable transfected with KITD816V, kindly provided by Drs. Patrice Dubreuil and Paulo De Sepulveda, Centre de Recherche en Cancérologie, Marseille, France) were loaded.

Membranes were incubated with goat polyclonal antibodies (1: 1000) raised against human c-kit (C-14; Santa Cruz Biotechnology, Dallas, TX) and human glyceraldehyde-3-phosphate dehydrogenase (GAPDH, V-18; Santa Cruz Biotechnology). The secondary antibody consisted of a peroxidase-conjugated anti-goat IgG (Merck Spa, Milano, Italy). The peroxide signal was detected using the Super Signal West Pico Chemiluminescent Substrate Kit (Thermo Fisher Scientific).

Images were captured by a Canon MG 5150 (Canon, Tokyo, Japan), and the integrated optimal density of each band was measured with the program ImageJ (U.S. National Institutes of Health, Bethesda, MD). Data were normalized with GAPDH values, and the band corresponding to TF1 KITD816V was used as a reference.

Plasmid Construct and Dual-Luciferase Reporter Assay. Part of the canine KIT proximal promoter (-228/-24) was subcloned, at the KpnI/SacI sites, into the reporter plasmid pGL4.10 expressing firefly luciferase (Promega). Two different plasmids (pGL4.104kit_A and pGL4.104kit_G) were obtained, according to the polymorphism detected in d_kit2 sequence in position -159 (Da Ros et al., 2014). Each plasmid was sequenced to check for the correct insert ligation. MDCK cells $\left(5.0 \times 10^{3}\right.$ cells in 96 -well plates) were cotransfected with $80 \mathrm{ng}$ of

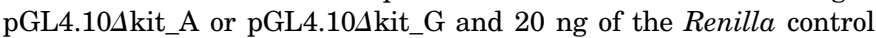
plasmid pGL4.74 (Promega) using the Fugene HD Transfection reagent (ratio 4:1; Promega).

Twenty-four hours later, the medium was changed, and the cells were incubated with AQ1 or AN6 (8 $\mu \mathrm{M}$ final concentration). After 48 hours, the Dual-Glo luciferase assay kit (Promega) was used to measure the luciferase activity. The firefly signal derived from the reporter plasmid was normalized to the Renilla luciferase signal.

Statistical Analysis. Data statistical analysis was performed by using GraphPad Prism version 5.00 for Windows (GraphPad Software, San Diego, CA). Dose-response curves and $\mathrm{IC}_{50}$ values were determined by nonlinear regression analysis, fitting a sigmoid dose-response curve. The data for the time-dependent constitutive expression of target genes were expressed as $n$-fold change of the value obtained at $\mathrm{T}_{6}$ and were analyzed with one-way analysis of variance (ANOVA) followed by Bonferroni's post-test. A two-way ANOVA followed by Bonferroni's post-test was used to analyze data from cells treated with G4 ligands to verify whether any difference in transcriptional response was dose and/or time dependent. Each $R Q$ value of treated cells was normalized to the average RQ of the respective time-control samples.

The immunoblotting data were expressed as a percentage of the control integrated density, where the control was represented by normal cells in culture. Variations between the cells exposed to DMSO and G4 ligands were statistically evaluated using Student's $t$ test. Transfection data were expressed as a ratio between luciferase firefly/luciferase Renilla control activation signal normalized to the control; the latter was represented by the empty vector or DMSO-treated cells. The observed variations were statistically evaluated using nonparametric one-way ANOVA followed either by Dunn's post-test (when a comparison between three groups was made) or nonparametric Student's $t$ test (when only two groups were considered). Overall, $P \leq 0.05$ was considered statistically significant.

\section{Results}

Sequencing of KIT Proximal Promoter in Canine C2 and NI-1 Cells. Before testing the effects of candidate G4 ligands, we verified whether $\mathrm{C} 2$ and NI-1 cells possessed the expected d_kit1 and d_kit2 sequences already characterized by Da Ros et al. (2014). In particular, we focused on nucleotide -159 , owing to a polymorphism $(-159 \mathrm{G}>\mathrm{A})$ that we previously noticed in a cohort of canine MCTs. The d_kit1 and d_kit2 sequences were the following: d_kit1, AGGGAGGGCGCCGGGAGGAGGG; d_kit2, AGGAGGGGCGCGGGGAAGGGG. Therefore, considering the nomenclature previously reported by Da Ros et al. (2014), it was inferred that C2 and NI-1 cells possess both d_kit1 and d_kit2_A16 sequences.

Interaction of G4 Forming Sequences with Selected Ligands. As we previously reported, the conformational features of G-rich domains of human and canine KIT promoters only partially overlap. In particular, although a general conservation was found between the kit1 domain of the two species, the conformational features of $\mathrm{h}$-kit2 and d_kit2_A16 significantly diverge. Therefore, we preliminarily explored the interaction of our two G4 ligands with canine sequences. Specifically, we assessed the G4 thermal stabilization induced by our ligands using a fluorescence melting assay, and the ligands binding to G4 using a fluorescence competitive displacement assay in which TO was used as a probe. Both protocols highlighted a binding profile of canine sequences relatively similar to the human one and confirmed a 
TABLE 2

Thermal stabilization of G-rich sequences of human and canine KIT promoter induced by $1 \mu \mathrm{M}$ of candidate ligands $\left(\Delta \mathrm{Tm}{ }^{\circ} \mathrm{C}\right)$ as well as of ligand concentrations $(\mu \mathrm{M})$ causing a $50 \%$ displacement of $\mathrm{TO}\left(\mathrm{EC}_{50}\right)$

\begin{tabular}{lccccc}
\hline Compound & h_kit1 & d_kit1 & h_kit2 & d_kit2_A16 & dsDNA \\
\hline AQ1 & & & & & \\
$\Delta \operatorname{Tm}\left({ }^{\circ} \mathrm{C}\right)$ & 13.1 & 18.7 & 15.3 & ND & 4.6 \\
$\mathrm{EC}_{50}(\mu \mathrm{M})$ & $0.32 \pm 0.05$ & $0.64 \pm 0.04$ & $0.35 \pm 0.05$ & $0.14 \pm 0.01$ & $3.66 \pm 0.08$ \\
$\mathrm{AN6}$ & 5.2 & 1.4 & & & \\
$\Delta \operatorname{Tm}\left({ }^{\circ} \mathrm{C}\right)$ & $4.11 \pm 0.70$ & $5.71 \pm 0.46$ & $3.63 \pm 1.00$ & $5.11 \pm 0.29$ & $11.42 \pm 0.28$ \\
$\mathrm{EC}_{50}(\mu \mathrm{M})$ &
\end{tabular}

d_kit1, canine kit1 G4 forming sequence; d_kit2_A16, canine kit2 G4 forming sequence with the -159 G $>$ A single nucleotide polymorphism; dsDNA, random double-strand DNA; h_kit1: human kit1 G4 forming sequence; $h$ kit2, human kit2 G4 forming sequence; ND, no detectable melting transition via thermal denaturation profiles; TO, thiazole orange.

preferential binding of $\mathrm{AQ} 1$ to all the tested G-rich sequences (Table 2). The same behavior was noticed using a doublestranded DNA (dsDNA) that did not fold into G4, thus indicating the possible higher rate of off-target effects connected to the use of AQ1.

As a second step we decided to assess whether the observed G4 interaction was predictive of an interference with DNAprocessing enzymes. Thus, we analyzed the replication of template strands containing either the human or the canine kit1 and kit2 sequences. In this experimental system, G4 formation is expected to stop the elongation of a complementary primer by Taq polymerase (Polymerase Stop assay). Consistently, increasing concentrations of our ligands in the reaction mixture resulted in a progressive reduction of the full-length product and in the parallel formation of an arrest product corresponding to the primer elongation up to the G-rich domain. The intensities of corresponding bands were quantified and the percentage of the truncated form over the

A

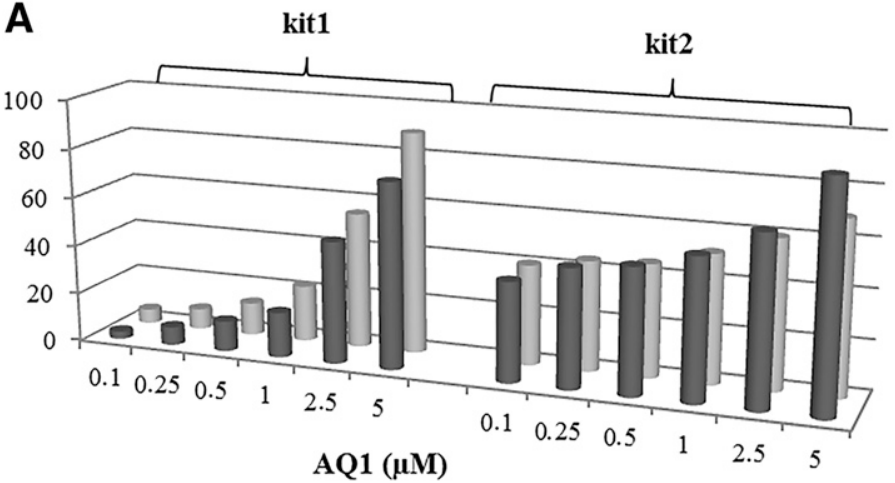

B

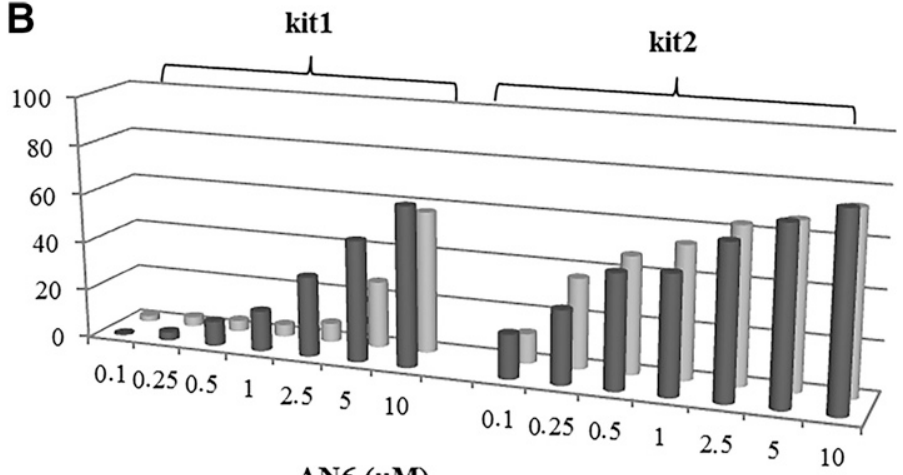

total elongated products was plotted as a function of ligand concentration (Fig. 1).

The effects elicited by the tested derivatives did not significantly differ between the two species. In particular, as already reported for human sequences and in agreement with the DNAbinding profile, AQ1 was the most effective in fully suppressing the elongation of all templates. Additionally, in the presence of low ligand concentrations, kit2 always represented the preferential arrest site when compared with kit1.

Of note, these results were obtained using simplified models that take into account only the single-strand G-rich sequences; inside the cell, the promoter is essentially present as a doublestranded DNA. This represents a challenge for G4 ligands. In fact, to be physiologically effective they must support a dsDNA unpairing to free the G-rich strand and to promote its G4 folding.

To verify the ability of our compounds to shift the DNA conformational equilibria from ds to G4 folding, we performed

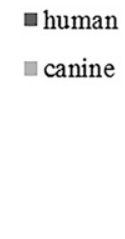

Fig. 1. Quantification of the arrest product detected by polymerase stop assay. Experiments were performed with increasing concentration of (A) AQ1 or (B) AN6 and using template strands containing the human or canine kit1 or kit2 sequences. Errors were $\pm 10 \%$. a human

घanine 
a fluorescence melting study. As target sequences we used both the human and canine G-rich domains previously paired to their complementary C-rich strands. In our system, the G-rich strands were labeled at $3^{\prime}$ and $5^{\prime}$ with a fluorophore and a quencher, respectively; this allowed monitoring the melting of the double helix whenever it was associated with the formation of a G4 structure as a remarkable quenching of the fluorescence signal (Rachwal and Fox, 2007, Bhattacharjee et al., 2011, Wang and Wei, 2013). In our experimental conditions ( $50 \mathrm{mM} \mathrm{KCl),}$ the conversion of dsDNA into a G4 structure was evident above $60^{\circ} \mathrm{C}$ (Fig. 2). A further increase in the temperature was also expected to result in G4 denaturation (Alberti and Mergny, 2003; Koirala et al., 2013), but in our experimental conditions this event was well resolved only with the $h \_k i t 2$ sequence. This means that for the other sequences the thermal stability of the G4 folded form was not significantly higher than the dsDNA.

We repeated the same protocol by including increasing concentrations of our ligands in the reaction mixture (Fig. 3). Overall, the presence of the ligands allowed us to properly detect both the ds-G4 conversion and the G4 melting, thus highlighting a preferential stabilization of the tetrahelical conformation. The only exception was represented by the d_kit2_A16 sequence, where G4 melting was observed only at the highest tested AN6 concentration.

Cytotoxicity. By using the Alamar Blue cytotoxicity test, a sigmoidal dose-response curve was built up for each ligand in canine $\mathrm{C} 2$ cell line, and the corresponding $\mathrm{IC}_{50}$ value was identified. Figure 4 shows the dose-response curves for AQ1 (Fig. 4A) and AN6 (Fig. 4B). The $\mathrm{IC}_{50}$ values we obtained were $1.27 \mu \mathrm{M}\left(\mathrm{R}^{2}: 0.9813\right)$ and $5.87 \mu \mathrm{M}\left(\mathrm{R}^{2}: 0.9721\right)$ for $\mathrm{AQ} 1$ and AN6, respectively.

The results of the confirmatory cytotoxicity assays in the NI-1 cell line (dose-response curves and corresponding $\mathrm{IC}_{50}$ values) are reported in Supplemental Fig. 1. Both ligands were proved to be cytotoxic. This MCT cell line was more sensitive when compared with the $\mathrm{C} 2$ cells, as shown by the lower $\mathrm{IC}_{50}$ values we obtained $(0.23$ and $2 \mu \mathrm{M}$ for $\mathrm{AQ} 1$ and AN6, respectively).

Time-Dependent Constitutive Expression of Target Genes. Target gene mRNA levels are likely to change with

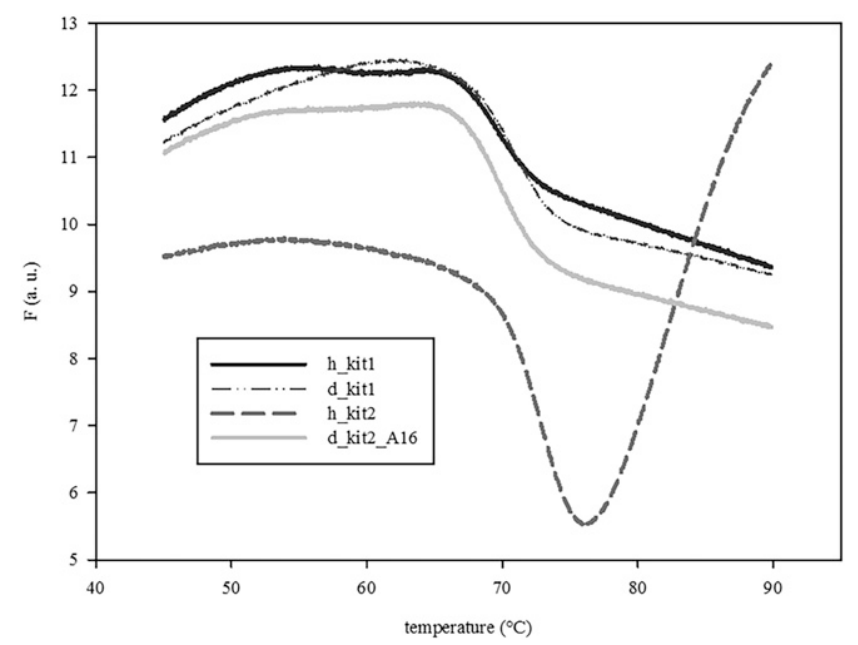

Fig. 2. Denaturation profiles of double-stranded form of human and canine KIT sequences. Data were acquired in the presence of $50 \mathrm{mM} \mathrm{KCl}$.
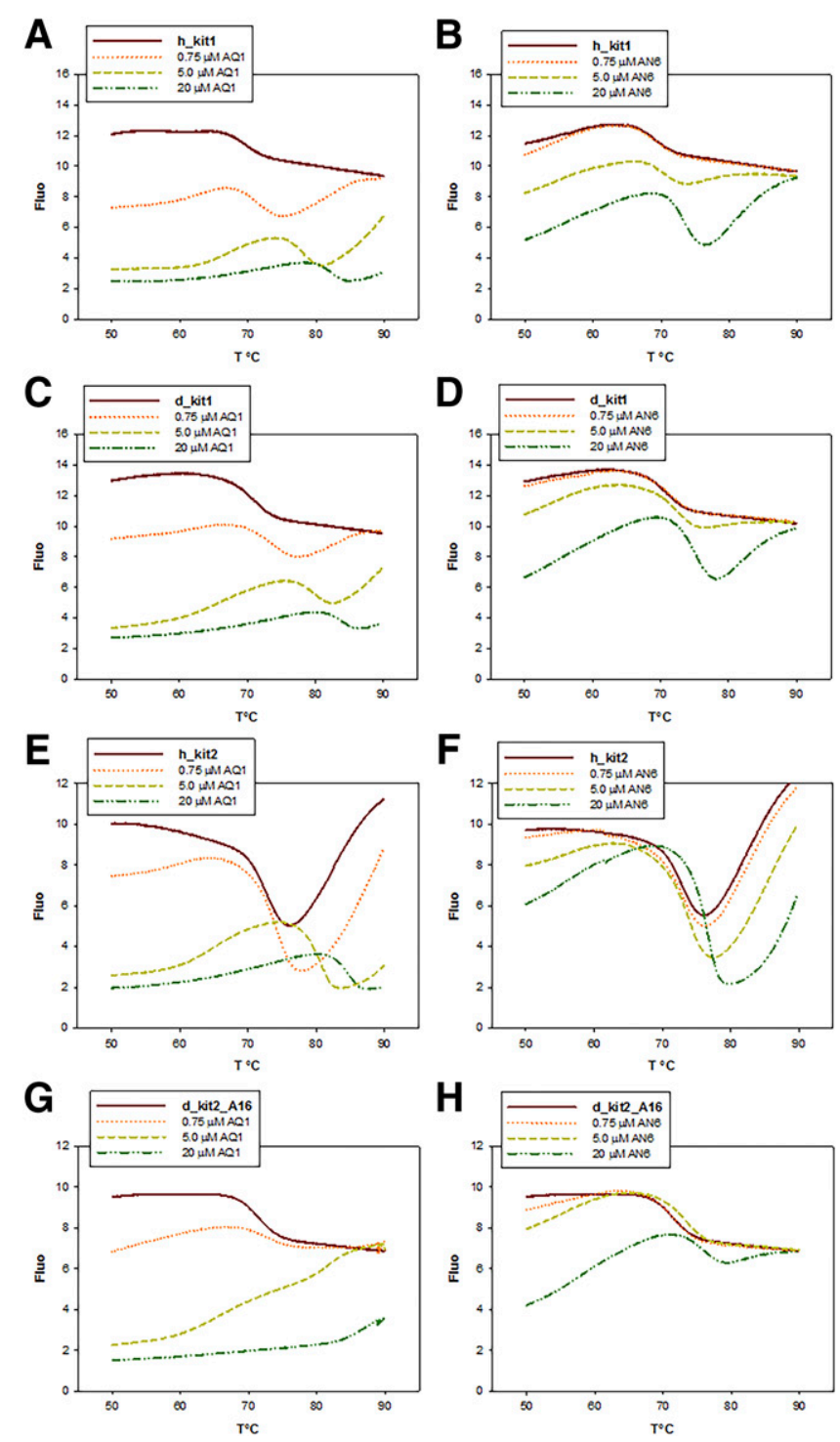

Fig. 3. Denaturation profiles of the double-stranded form of human and canine $K I T$ sequences. Data were acquired in the presence of $50 \mathrm{mM} \mathrm{KCl}$ and increasing concentrations of AQ1 or AN6. (A) $h$ _kit1 and AQ1. (B) h_kit1 and AN6. (C) d_kit1 and AQ1. (D) d_kit1 and AN6. (E) h_kit2 and AQ1. (F) h_kit2 and AN6. (G) d_kit2_A16 and AQ1. (H) d_kit2_A16 and AN6.

time of culture, so we measured in both the canine MCT cell lines the possible time-dependent changes (from $\geq 6$ to 96 hours) in the constitutive expression of KIT and other five genes known to contain putative G4 structures in their promoter. Overall, we noticed some differences between the two cell lines.

In the $\mathrm{C} 2$ cell line (Fig. 5), the mRNA levels of KIT and $K R A S$ were never affected by the time of culture, although we saw an overall decrease for BCL2, MYC, and TERT. Specifically, BCL2 mRNA levels were statistically significantly decreased at $\mathrm{T}_{96}$ versus $\mathrm{T}_{24}$ and $\mathrm{T}_{48}(P<0.05)$. The constitutive expression of $M Y C$ was significantly decreased at $\mathrm{T}_{48}, \mathrm{~T}_{72}$, and $\mathrm{T}_{96}$ compared with $\mathrm{T}_{6}(P<0.05)$. TERT showed a higher pattern of expression up to $\mathrm{T}_{24}$; it showed a significant decrease at $\mathrm{T}_{96}$ compared with $\mathrm{T}_{6}$ and $\mathrm{T}_{24}(P<0.001)$. Finally, VEGFA was the unique gene to show a time-dependent up-regulation of its mRNA levels, reaching the level of significance at $\mathrm{T}_{96}$ versus $\mathrm{T}_{24}$ and $\mathrm{T}_{48}(P<0.001$ and $P<0.05$, respectively). 

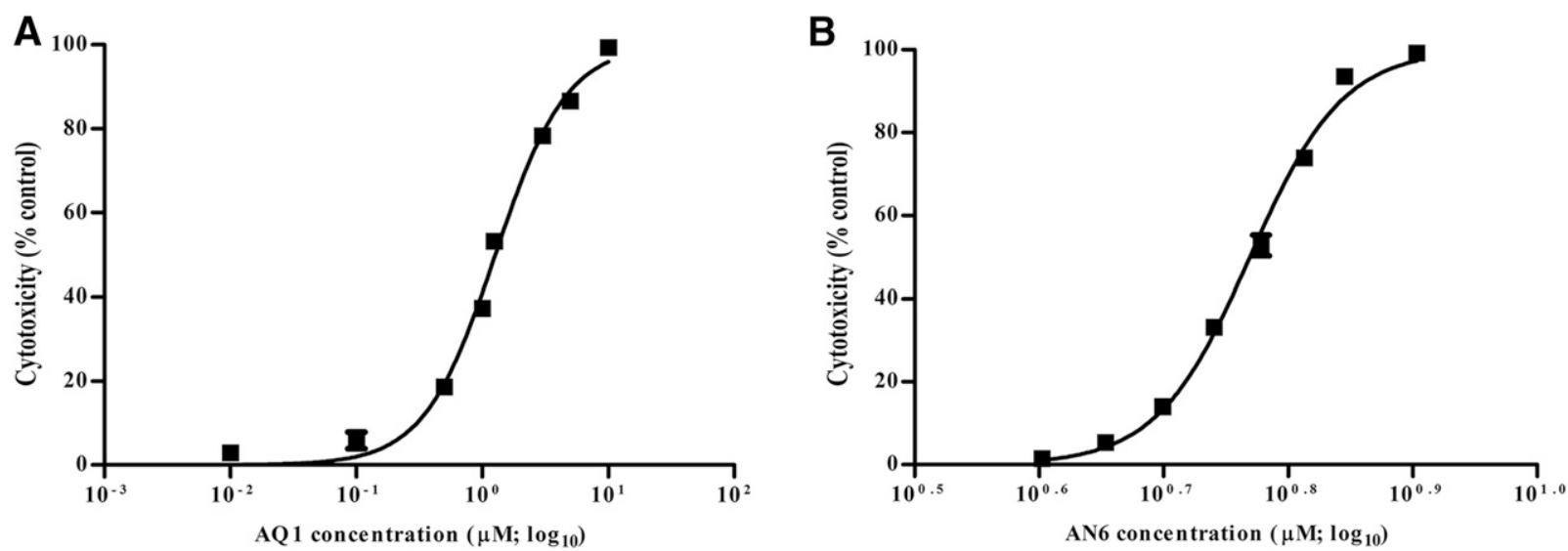

Fig. 4. Cytotoxicity (dose-response curves) of AQ1 and AN6 in the canine cancer C2 MCT cell line. C2 cells were exposed to (A) AQ1 and (B) AN6, and their cytotoxicity was measured using the Alamar Blue assay. Cytotoxicity was calculated as [100 - (T/control mean $\times 100)]$. Data are expressed as mean \pm S.D. of three independent experiments (each concentration performed six times) in different culture passages.

In the NI-1 cells (Supplemental Fig. 2), the KIT mRNA levels slightly increased with time $\left(\mathrm{T}_{6}\right.$ and $\mathrm{T}_{24}$ vs. $\left.\mathrm{T}_{96} ; P<0.05\right)$, but no time-dependent changes were ever noticed in the $B C L 2, K R A S$, or MYC mRNA levels. TERT showed a slight inhibition at $\mathrm{T}_{72}$ and $\mathrm{T}_{96}(P<0.05)$. We observed a time-dependent VEGFA up-regulation, reaching the level of statistical significance at $\mathrm{T}_{96}$ versus $\mathrm{T}_{6}(P<0.05)$.
Taking these results into consideration as a whole, we decided to measure the transcriptional effects of two subcytotoxic concentrations of AQ1 and AN6 (corresponding to one-third and two-thirds of their $\mathrm{IC}_{50}$ ) at three different time points $\left(\mathrm{T}_{6}, \mathrm{~T}_{12}\right.$, and $\mathrm{T}_{24}$ hours after exposure) in both cell lines.

Transcriptional Effects of G4 Ligands and Confirmatory Post-translational Investigations. An overall dose-dependent

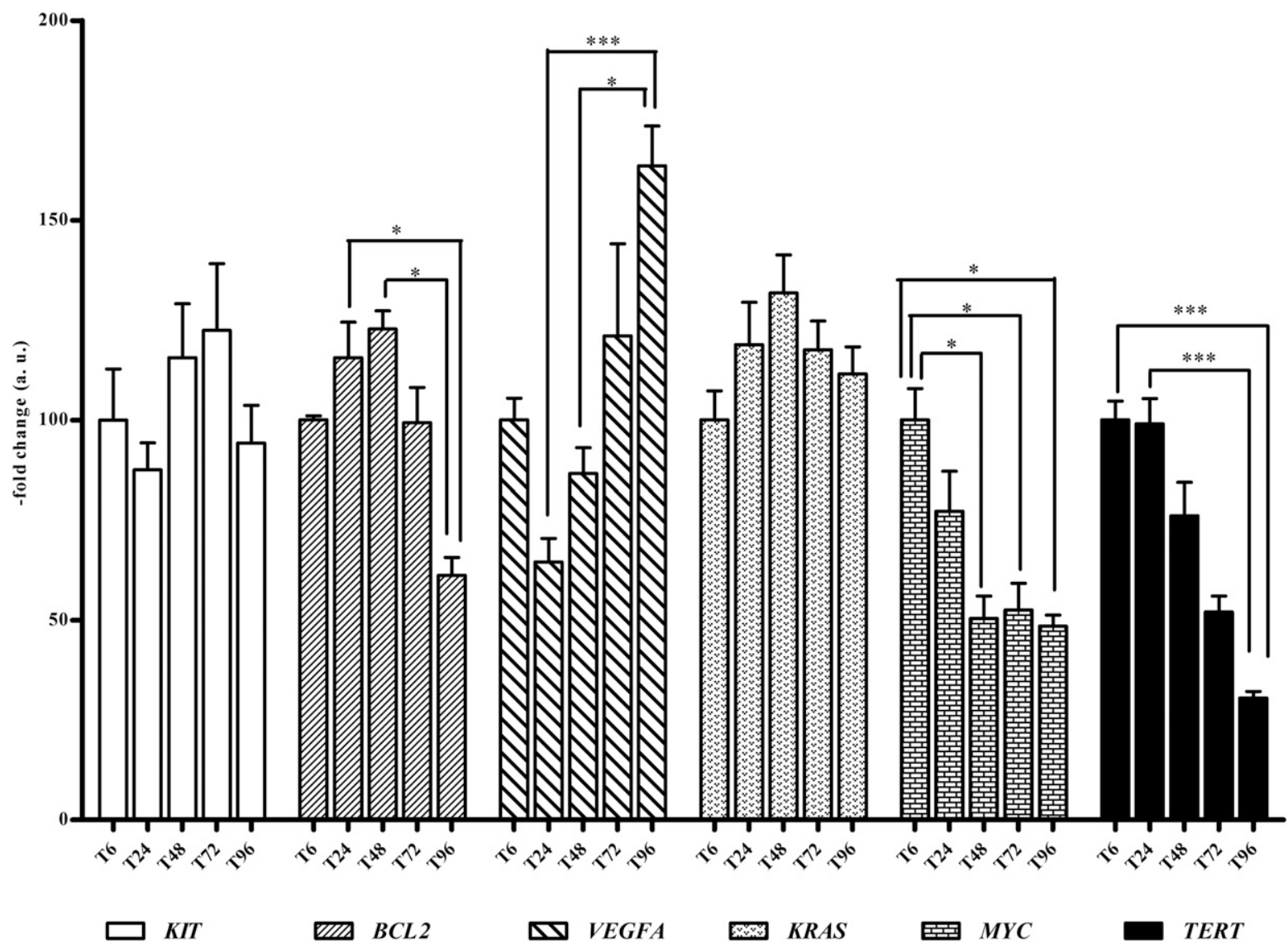

Fig. 5. Effects of culturing time (6, 24, 48, 72, and 96 hours) on the expression of genes containing putative G4 structures in their promoter in the canine C2 MCT cell line. Total RNA was isolated from C2 cells, and KIT, BCL2, VEGFA, KRAS, MYC, and TERT mRNA levels were measured using qRT-PCR. Data (arithmetic mean \pm S.D.) are expressed as $n$-fold change (AU, arbitrary units) normalized to the RQ mean value of cells stopped at $T_{6}$, to which an arbitrary value of 100 was assigned. The experiments were performed in triplicate; for each experiment, two biologic replicates were included. The one-way ANOVA was used to measure the statistical differences between different culture times. $* P<0.05 ; * * * P<0.001$. 
A

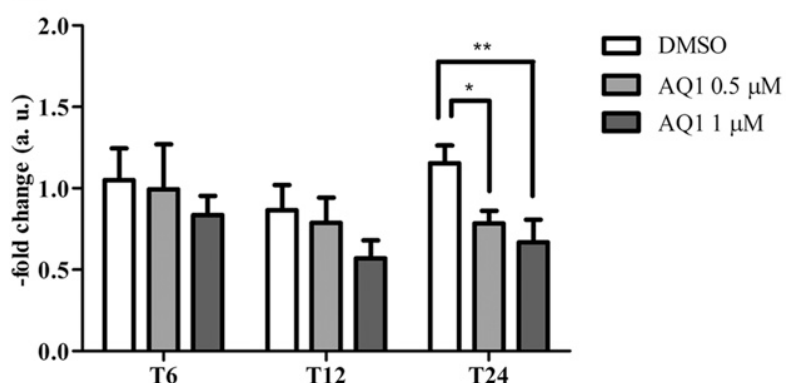

B

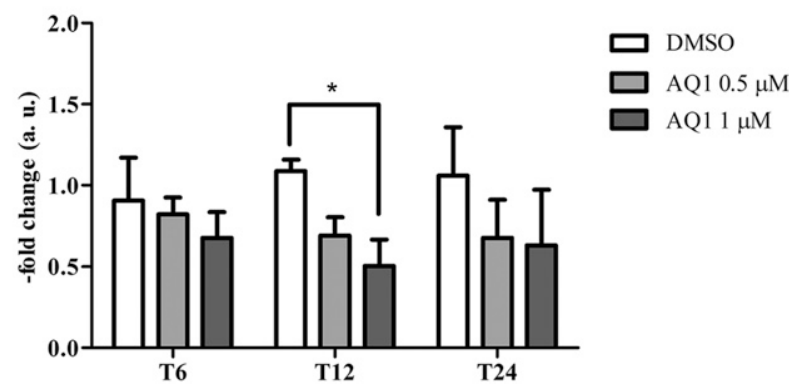

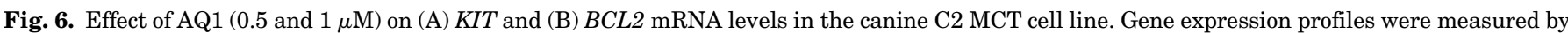

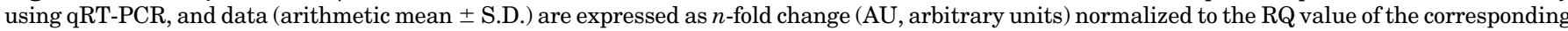

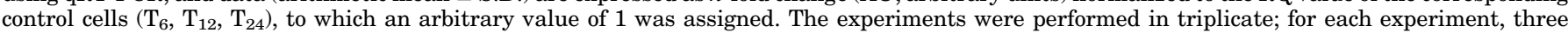

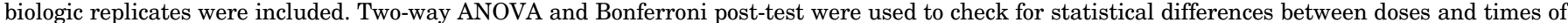
treatment. $* P<0.05 ; * * P<0.01$.

decrease of KIT mRNA was observed in C2 cells exposed to AQ1, reaching the level of statistical significance at $\mathrm{T}_{24}(P<0.05, P<$ 0.01 ; Fig. 6A). No differences were ever recorded for the other target genes (data not shown) except for BCL2, for which an overall and moderate down-regulation was noticed. The decrease was statistically significant at the highest dose at $\mathrm{T}_{12}(P<0.05$ : Fig. 6B).

Because KIT was the main focus of this study, we performed a confirmatory set of similar experiments using a higher AQ1 concentration $(1.5 \mu \mathrm{M})$. We observed a greater gene downregulation that was statistically significant at earlier time points ( $\mathrm{T}_{6}$ and $\mathrm{T}_{12} ; P<0.05$, Fig. 7A). These transcriptional results were also confirmed at the protein level, as shown in Fig. 7, B and C. The densitometric analysis showed a statistically significant $(P<0.05) 2$-fold reduction of c-kit protein after the treatment with AQ1.

With AN6, we observed an overall and dose-dependent inhibition of KIT mRNA levels. This down-regulation was always statistically significant $\left(P<0.01\right.$ at $\mathrm{T}_{6}$ and $\mathrm{T}_{24}$;
$P<0.05$ at $\left.\mathrm{T}_{12}\right)$ at the highest ligand concentration $(4 \mu \mathrm{M})$. The down-regulation was limited to $\mathrm{T}_{24}(P<0.05)$ in the cells exposed to $2 \mu \mathrm{M}$ AN6 (Fig. 8A). The confirmatory posttranscriptional investigations showed a 2-fold statistically significant $(P<0.05)$ decrease of c-kit protein after 24 hours of exposure with $4 \mu \mathrm{M}$ AN6 (Fig. 8, B and C). The other target genes showed neither time- or dose-dependent significant variations of mRNA levels (data not shown).

Fairly similar confirmatory results were obtained with NI-1 cells. Supplemental Fig. 3, A and B, shows the KIT and BCL2 mRNA levels measured at different time points after the exposure of NI-1 cells to two AQ1 subcytotoxic concentrations. A statistically significant down-regulation of the KIT mRNA level was detected at $\mathrm{T}_{6}(P<0.001)$ and $\mathrm{T}_{12}(P<0.01, P<0.001$; Supplemental Fig. 3A). Statistically significant BCL2 downregulation was observed at $\mathrm{T}_{6}$ and only at the highest AQ1 concentration $(P<0.01$; Supplemental Fig. 3B). No differences were recorded for the other target genes (data not shown). When the NI-1 cells were treated with a higher AQ1
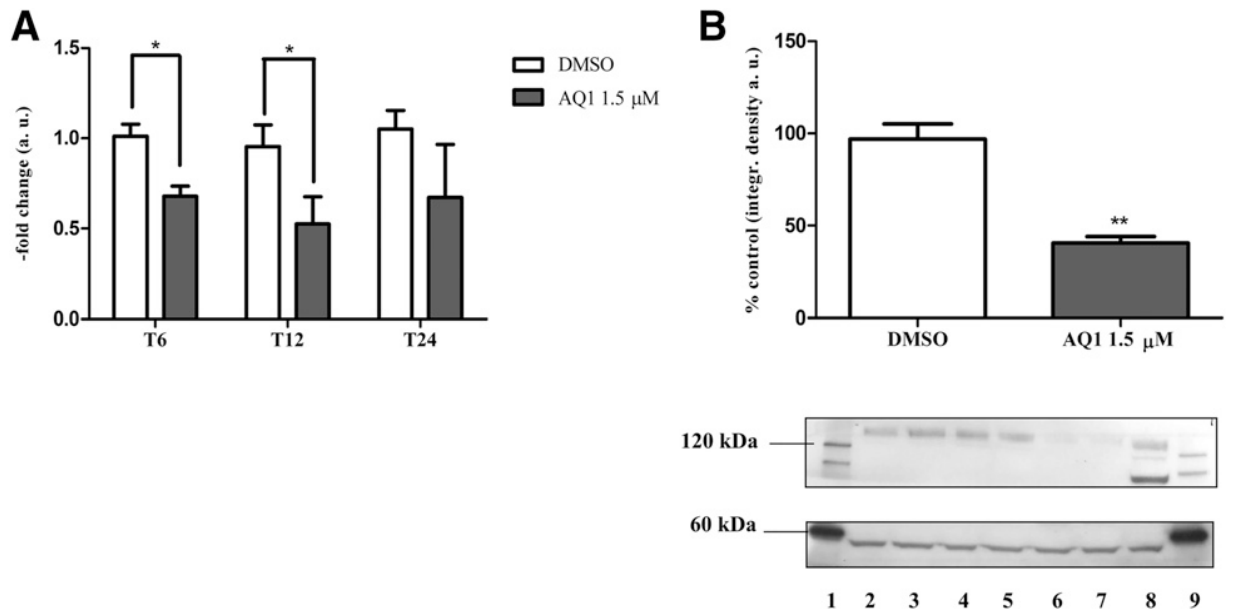

Fig. 7. Effect of AQ1 (1.5 $\mu \mathrm{M})$ on (A) KIT gene expression and (B and C) c-kit protein in the canine C2 MCT cell line. (A) KIT mRNA levels were measured by qRT-PCR, and the data (arithmetic mean \pm S.D.) are expressed as $n$-fold change (AU, arbitrary units) normalized to the RQ of control cells at each time $\left(\mathrm{T}_{6}, \mathrm{~T}_{12}, \mathrm{~T}_{24}\right)$, to which an arbitrary value of 1 was assigned. The experiments were performed in triplicate; for each experiment, three biologic replicates were included. Two-way ANOVA and Bonferroni post-test were used to find any statistically significant differences between doses and times of treatment. (B) The effect of AQ1 on c-kit protein amount was measured by immunoblotting, and the data are expressed as $n$-fold change (AU) with respect to the untreated cells' densitometry. Experiments were performed in triplicate; for each experiment, three biologic replicates were included. Student's $t$ test was used to check for statistically significant differences between the cells treated with AQ1 and those treated with vehicle only (DMSO). ${ }^{*} P<0.05 ; * * P<0.01$. (C) Representative immunoblot image. Legend: 1 , ladder; $2-3$, control cells; 4-5, DMSO (vehicle); 6-7, cells exposed to AQ1 (24 hours); 8, TF1 control cells; 9 , ladder. 


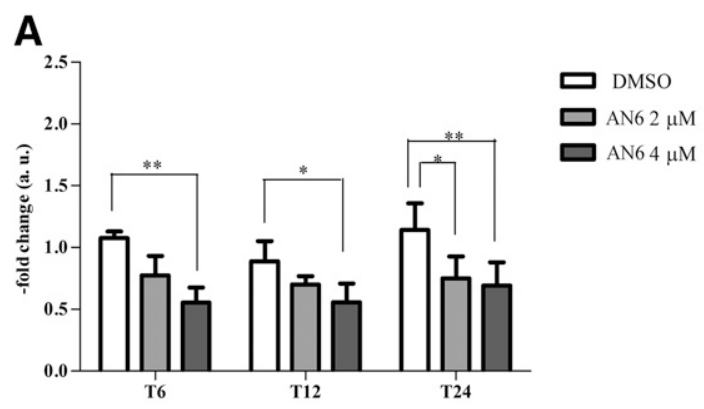

B

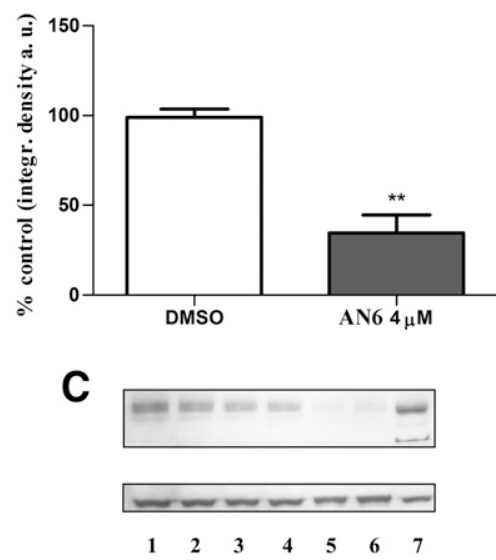

Fig. 8. Effect of AN6 ( 2 and $4 \mu \mathrm{M}$ ) on (A) KIT mRNA and (B and C) c-kit protein in the canine C2 MCT cell line. (A) KIT mRNA levels were measured by qRT-PCR, and the data (arithmetic mean \pm S.D.) are expressed as $n$-fold change (AU, arbitrary units) normalized to the RQ of control cells at each time $\left(\mathrm{T}_{6}, \mathrm{~T}_{12}, \mathrm{~T}_{24}\right)$, to which an arbitrary value of 1 was assigned. The experiments were performed in triplicate; for each experiment, three biologic replicates were included. Two-way ANOVA and Bonferroni post-test were used to find any statistically significant differences between doses and times of treatment. (B) The effect of AN6 on c-kit protein amount was measured by immunoblotting, and the data are expressed as $n$-fold change (AU) with respect to the untreated cells' densitometry. The experiments were performed in triplicate; for each experiment, three biologic replicates were included. Student's $t$ test was used to check for statistically significant differences between cells treated with AN6 and those treated with vehicle only (DMSO). ${ }^{*} P<0.05$; $* * P<0.01$. (C) Representative immunoblot image. Legend: 1-2, control cells; 3-4, DMSO (vehicle); 5-6, cells exposed to AN6 (24 hours); 7 , TF1 control cells.

concentration, greater gene down-regulation was noticed at the same time points $\left(P<0.001\right.$ and $P<0.05$ at $\mathrm{T}_{6}$ and $\mathrm{T}_{12}$, respectively; Supplemental Fig. 4A). These transcriptional results were also confirmed at the protein level (Supplemental Fig. 4B). The densitometric analysis showed a statistically significant $(P<0.01) 2$-fold reduction of c-kit protein after the treatment with AQ1.

The treatment with AN6 led to a statistically significant inhibition of KIT expression at a higher dose and within the first 12 hours of treatment $\left(P<0.01\right.$ and $P<0.001$ at $\mathrm{T}_{6}$ and $\mathrm{T}_{12}$, respectively; Supplemental Fig. 5A). The post-transcriptional investigations corroborated the transcriptional results, with a statistically significant $(P<0.05)$ decrease of c-kit protein after

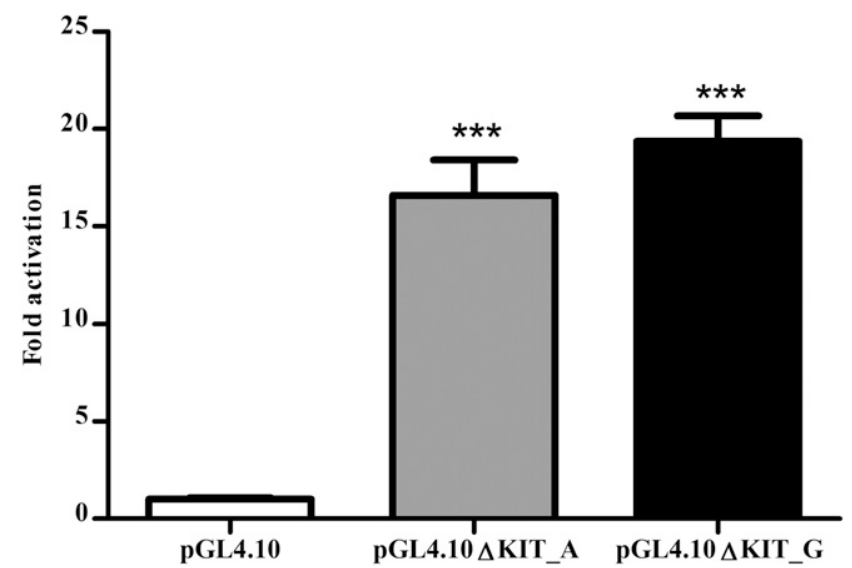

Fig. 9. Presence of transcription binding sites in canine $K I T$ proximal promoter. KIT proximal promoter was cloned into a pGL4.10 luciferase vector and transfected into MDCK cells. The transcriptional activity was assessed by using dual luciferase assays. Data are expressed as the ratio of Firefly/Renilla (AU, arbitrary units) normalized against cells transfected with empty pGL4.10 vector. The data (mean \pm S.D.) represent three independent experiments, each performed six times, expressed as fold activation (AU) to which an arbitrary value of 1 was assigned. $* * * P<0.001$.
24 hours of exposure to AN6 treatment (Supplemental Fig. 5B). The other target genes showed no time- or dose-dependent significant variations of their mRNA levels (data not shown).

Dual-Luciferase Reporter Assay. To explore whether the effects of AQ1 and AN6 on KIT expression were consequent to the ligand binding to the KIT proximal promoter, a canine noncancerous cell line (MDCK) was transfected with the canine $K I T$ proximal promoter sequence cloned upstream of a luciferase reporter gene. Cells transfected with the plasmid containing the canine KIT proximal promoter increased more than 15-fold $(P<$ $0.001)$ the luciferase production when compared with those transfected with the empty pGL4.10 reporter plasmid (Fig. 9). This result was indicative of the presence of transcription binding sites in the DNA sequence immediately upstream of the transcription starting site, just where d_kit1 a d_kit2_A16 G4 are located.

To find the suitable subcytotoxic concentration of AQ1 and AN6 to be used in gene reporter assays, we exposed MDCK cells for 48 hours to increasing concentrations of each ligand (from $\geq 0.05$ to $12 \mu \mathrm{M}$; Fig. 10, A and B). Our results proved MDCK cells are highly resistant to the treatment with the two candidate G4 ligands. Indeed, both AQ1 and AN6 halved the cell viability at $10 \mu \mathrm{M}$. Specifically, the cells exposed to $8 \mu \mathrm{M}$ AQ1 showed about $70 \%$ of viability, and no cytotoxicity was noticed with $8 \mu \mathrm{M} \mathrm{AN} 6$.

After the transfection of MDCK cells with pGL4.10 $\Delta$ kit_A or pGL4.10skit_G plasmid for 24 hours, and the ensuing incubation for 48 hours with both G4 ligands ( $8 \mu \mathrm{M}$ final concentration), AQ1 did not modify substantially the luciferase activity (Fig. 10C). However, the luciferase was significantly inhibited $(P<0.001)$ by AN6 (Fig. 10D). This inhibition was not influenced by the presence of the $\mathrm{G}>\mathrm{A}$ polymorphism.

\section{Discussion}

The presence of G4 structures in genome regions that are essential for cell proliferation attracted the interest of researchers as potential targets for anticancer agents. As a result, 

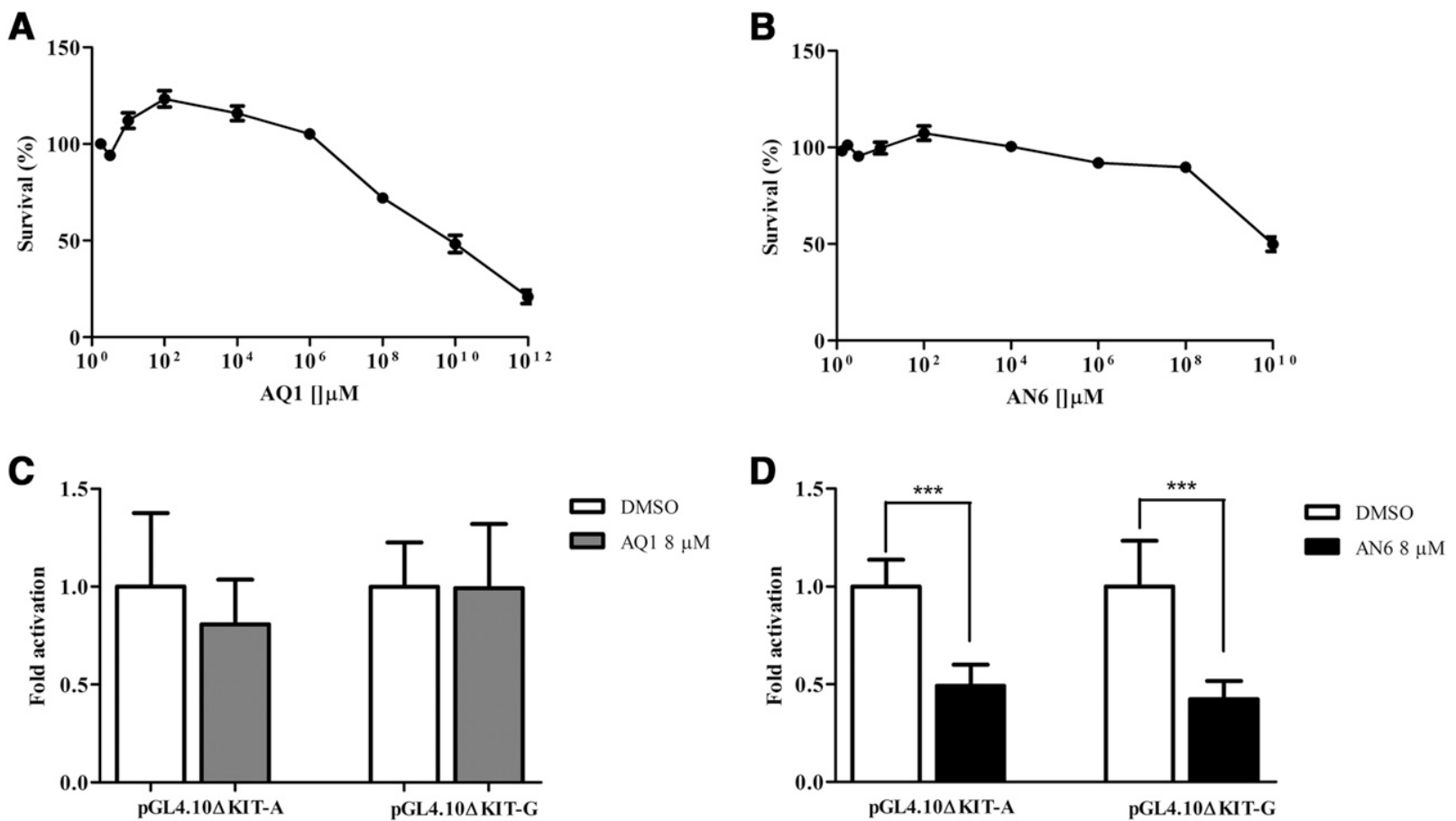

Fig. 10. Effect of the exposure to increasing concentrations of (A) AQ1 and (B) AN6 on canine MDCK (noncancer) cell line proliferation and dualluciferase reporter assays (C and D). Data referring to the effect of increasing concentrations of (A) AQ1 and (B) AN6 upon MDCK cell proliferation after 48 hours of incubation. Data are expressed as the percentage of survival cells (T/mean controls $\times 100$ ), and they represent the mean \pm S.D. of three independent experiments, each performed six times. (C and D) Luciferase reporter assays of MDCK cells exposed to either (C) AQ1 or (D) AN6. Data are expressed as the ratio Firefly/Renilla (AU, arbitrary units) normalized against cells treated with the vehicle (DMSO). The experiments were performed in triplicate; for each experiment, six biologic replicates were included. Nonparametric Student's $t$ test was used to check for statistical differences between DMSO-treated and ligand-treated cells. ${ }^{* * *} P<0.001$.

a number of small molecules showing either good G4 interaction or promising cytotoxic activity in vitro were considered as candidate anticancer drugs.

Overall, the fundamental similarities between canine and human tumors suggest their possible translation from one species to the other. However, this strategy can easily fail when we deal with G4-directed ligands. Indeed, these nucleic acid structures are highly polymorphic, and even negligible sequence mutations can cause large changes in G4 topology and stability. Moreover, this can easily result also in the recruitment of the transcriptional machinery, where different protein components are involved.

To shed light on these events, a comparative and translational approach to cancer research is critically important to ultimately derive benefits for both species and to develop new candidate G4 ligands with realistic drug-like structures, higher selectivity, and reduced side effects. Here, we considered that the proximal promoter of human and canine genes presents a relevant degree of sequence homology, which does not exclude some partial structural rearrangements. Additionally, mutations located within promoter G-rich domains might be responsible for a partial rearrangement of the associated G4 structures. Ultimately, this might affect their recognition by small G4 ligands, which consequently could lead to distinct molecular events (Siddiqui-Jain et al., 2002; Patel et al., 2007; Tian et al., 2010). Nevertheless, this was not the case for human and canine $K I T$; in fact, the interspecies comparison of binding properties of the selected G4 ligands to the canine and human sequences showed only minor variations.

In both species, AQ1 proved to be a stronger binder in comparison with AN6, recognizing both G4 and dsDNA.
As already mentioned, the interaction of AN6 with the double helix was extremely reduced, so we might assume it to be a more selective G4 binder. Despite this difference in DNA recognition, the AN6-kit2 complex appears to be an interference element for DNA processing enzyme as good as the AQ1-kit2. Thus, we might postulate that treatment of canine or human cancer cells lines with AQ1 or AN6 would cause similar effects on oncogene expression, but this was not the case.

When using AQ1, we saw significant down-regulation of KIT mRNA after 24 hours of exposure to two subcytotoxic concentrations ( 0.5 and $1 \mu \mathrm{M})$. Further, we observed a timeindependent decrease of KIT gene expression at a concentration close to the corresponding $\mathrm{IC}_{50}$ value $(1.5 \mu \mathrm{M})$. This gene down-regulation was confirmed at the protein level when the $\mathrm{C} 2$ cells were exposed to the same AQ1 concentration $(1.5 \mu \mathrm{M})$.

In confirmatory studies made on a second canine MCT cell line, NI-1, the cell proliferation was substantially inhibited at lower AQ1 concentrations. Moreover, and fairly similar to C2 cell line, the exposure to AQ1 subcytotoxic concentrations resulted in a significant down-regulation of KIT mRNA levels and c-kit protein. Even so, this level of inhibition in canine models is less pronounced when compared with the inhibition obtained in the human mast cell leukemia cell line HMC1.2 (i.e., 2-fold vs. 5-fold decrease in dog vs. human cell line, respectively, Zorzan et al., 2016).

Concerning the selectivity of AQ1 transcriptional effects, we screened other oncogenes containing putative G4 structures in their promoter (MYC, VEGFA, KRAS, BCL2, and TERT). Overall, only $B C L 2$ showed a trend to mRNA down-regulation in both canine cell lines. This result was not unexpected-in fact, AQ1 causes a marked inhibition of BCL2 mRNA levels in 
human cell lines as well (Zorzan et al., 2016). Moreover, some anthraquinone derivatives have been shown to induce apoptosis in vitro, a phenomenon that usually implies a decrease of BCL2 mRNA/protein (Huang et al., 2007, 2014; Hasan et al., 2011; Dong et al., 2017). This promising picture was not supported by luciferase reporter assay showing an extremely reduced capability of AQ1 to decrease the luciferase production even at the highest tested concentrations.

Considering the results we obtained as a whole, it is conceivable to hypothesize that the mild inhibition observed in canine KIT mRNA and protein after exposure to AQ1 might not univocally derive from the interaction between the ligand and the G4 in the promoter. Rather, it might be a consequence of other molecular mechanisms related to the cellular response to anticancer drugs such as TKIs and doxorubicin (van de Ven et al., 2011; Yamada et al., 2011; Rossi et al., 2013; Milovancev et al., 2016).

In line with the lower DNA-binding affinity and with previous data obtained in human cell lines, AN6 was less cytotoxic than AQ1 in C2 and NI-1 cells. Despite this, it significantly decreased KIT mRNA levels in both cell lines. Additionally, this transcriptional down-regulation was confirmed at the protein level. Interestingly, the gene reporter assay showed an inhibition of luciferase activity after the exposure of MDCK cells to AN6.

Taken as a whole, these results would confirm the activity of AN6 on canine KIT proximal promoter, although this behavior was quite unexpected. Indeed, in human cell lines exposed to AN6, neither a KIT transcriptional inhibition nor a reduction of the coded c-kit protein has ever been observed (Zorzan et al., 2016). The apparent binding affinity for canine G4 domains was AQ1 > AN6. The anthracene derivative proved to be a better KIT transcriptional down-regulator in canine cell lines. It is also worth mentioning that the opposite behavior was previously observed in human cell lines. To rationalize this picture, it is worth underlining that: 1 ) the conformational features of canine and human promoter sequences are perfectly overlapping for kit1 but slightly different for kit2, and 2) in terms of conformational rearrangements, kit2 is more sensitive to the presence of the ligands, which favors the impairment of DNA processing.

Merging all these data we can try to explain the different chemicobiologic behavior we noticed in human and canine cells after exposure to G4 candidate ligands. If we consider that the main difference between human and canine promoter rests in a preferential shift of the structural equilibrium toward the double-stranded form for d_kit2_A16 in contrast to G4 as in h_kit2, and that AQ1 poorly discriminates between these two different nucleic acid structural arrangements, it is tempting to attribute the persistence of luciferase production in transfected cells treated with AQ1 to its inability to convert the paired d_kit2_A16 into a G4. This explanation would further reinforce the importance of G4 domains in KIT proximal promoter as regulatory elements.

Nevertheless, we cannot forget that the observed differences in the biologic effects of the two tested compounds might reflect species-differences in susceptibility (human cells answer otherwise to AN6) and/or the possible involvement of other signaling pathways (BCL2 and apoptosis). Further studies are clearly needed on the molecular mechanisms resulting from the interaction of these ligands with canine KIT G4 structures. For example, chromatin immunoprecipitation might demonstrate whether AN6 (but also AQ1) really binds to d_kit1 and d_kit2, impeding the binding with specific protein 1 (Sp1) site. Additionally, it is known that approximately $30 \%-40 \%$ of human gene promoters contain a putative G4 motif, but no information is currently available about the canine genome.

Therefore, we should implement the molecular characterization of genes containing potential G4 structures that are overexpressed in MCT cell lines (i.e., other oncogenes such as TERT or PDGFA) to ascertain which cellular targets are primarily responsible for the inhibition of tumor cell growth by the G4 ligands. In this scenario, next-generation sequencing technologies (e.g., RNA-Seq) might help to unveil specific off-targets of AQ1 and AN6 in canine MCT and noncancer cells, as KIT is apparently not the only one. Another strategy is represented by the development of highly selective G4 ligands, thus avoiding an overall inhibition of gene transcription, potentially resulting in nonspecific toxicity.

In conclusion, to the best of our knowledge, ours is the first in vitro study showing how two candidate G4 ligands (AQ1 and AN6), formerly screened in human cells, down-regulate KIT expression in canine KIT-dependent MCT cell lines. The anthracene derivative AN6 may represent a promising candidate to decrease $K I T$ expression in canine $K I T$-dependent tumors such as MCTs.

\section{Acknowledgments}

We thank Dr. Patrice Dubreuil, Peter Valent, Dr. Emir Hadzijusufovic, and Dr. Michael Willmann for providing the C2 and NI-1 cell lines. We gratefully acknowledge undergraduate students Giulia Marostica and Valentina Michielon for their help in cell culturing and fine tuning the qRT-PCR and immunoblotting assays, respectively.

\section{Authorship Contributions}

Participated in research design: Giantin, Palumbo, Sissi, Dacasto. Conducted experiments: Zorzan, Da Ros, Shahidian, Guerra.

Performed data analysis: Zorzan, Da Ros.

Wrote or contributed to the writing of the manuscript: Zorzan, Da Ros, Giantin, Sissi, Dacasto.

\section{References}

Alberti P and Mergny JL (2003) DNA duplex-quadruplex exchange as the basis for a nanomolecular machine. Proc Natl Acad Sci USA 100:1569-1573.

Aresu L, Giantin M, Morello E, Vascellari M, Castagnaro M, Lopparelli R, Zancanella V, Granato A, Garbisa S, Aricò A, et al. (2011) Matrix metalloproteinases and their inhibitors in canine mammary tumors. BMC Vet Res 7:33-43.

Balasubramanian S, Hurley LH, and Neidle S (2011) Targeting G-quadruplexes in gene promoters: a novel anticancer strategy? Nat Rev Drug Discov 10:261-275.

Beaume N, Pathak R, Yadav VK, Kota S, Misra HS, Gautam HK, and Chowdhury S (2013) Genome-wide study predicts promoter-G4 DNA motifs regulate selective functions in bacteria: radioresistance of $D$. radiodurans involves G4 DNA-mediated regulation. Nucleic Acids Res 41:76-89.

Bejugam M, Sewitz S, Shirude PS, Rodriguez R, Shahid R, and Balasubramanian S (2007) Trisubstituted isoalloxazines as a new class of G-quadruplex binding ligands: small molecule regulation of c-kit oncogene expression. J Am Chem Soc 129: $12926-12927$.

Bhattacharjee AJ, Ahluwalia K, Taylor S, Jin O, Nicoludis JM, Buscaglia R, Brad Chaires J, Kornfilt DJ, Marquardt DG, and Yatsunyk LA (2011) Induction of G-quadruplex DNA structure by Zn(II) 5,10,15,20-tetrakis( $N$-methyl-4-pyridyl)porphyrin. Biochimie 93:1297-1309.

Bidzinska J, Cimino-Reale G, Zaffaroni N, and Folini M (2013) G-quadruplex structures in the human genome as novel therapeutic targets. Molecules 18: 12368-12395.

Bonkobara M (2015) Dysregulation of tyrosine kinases and use of imatinib in small animal practice. Vet $J$ 205:180-188.

Da Ros S, Zorzan E, Giantin M, Zorro Shahidian L, Palumbo M, Dacasto M, and Sissi C (2014) Sequencing and G-quadruplex folding of the canine protooncogene KIT promoter region: might dog be used as a model for human disease? PLoS One 9:e103876.

Dash J, Shirude PS, Hsu ST, and Balasubramanian S (2008) Diarylethynyl amides that recognize the parallel conformation of genomic promoter DNA G-quadruplexes. $J$ Am Chem Soc 130:15950-15956. 
Dong X, Fu J, Yin X, Qu C, Yang C, He H, and Ni J (2017) Induction of apoptosis in HepaRG cell line by aloe-emodin through generation of reactive oxygen species and the mitochondrial pathway. Cell Physiol Biochem 42:685-696.

Du Z, Kong P, Gao Y, and Li N (2007) Enrichment of G4 DNA motif in transcriptional regulatory region of chicken genome. Biochem Biophys Res Commun 354:1067-1070.

Dubreuil P, Letard S, Ciufolini M, Gros L, Humbert M, Castéran N, Borge L, Hajem B, Lermet A, Sippl W, et al. (2009) Masitinib (AB1010), a potent and selective tyrosine kinase inhibitor targeting KIT. PLoS One 4:e7258.

Fernando H, Reszka AP, Huppert J, Ladame S, Rankin S, Venkitaraman AR, Neidle S, and Balasubramanian S (2006) A conserved quadruplex motif located in a transcription activation site of the human c-kit oncogene. Biochemistry 45:7854-7860.

Gardner HL, Fenger JM, and London CA (2016) Dogs as a model for cancer. Annu Rev Anim Biosci 4:199-222.

Giantin M, Aresu L, Benali S, Aricò A, Morello EM, Martano M, Vascellari M, Castagnaro M, Lopparelli RM, Zancanella V, et al. (2012) Expression of matrix metalloproteinases, tissue inhibitors of metalloproteinases and vascular endothelial growth factor in canine mast cell tumours. J Comp Pathol 147:419-429.

Giantin M, Baratto C, Marconato L, Vascellari M, Mutinelli F, Dacasto M, and Granato A (2016) Transcriptomic analysis identified up-regulation of a solute carrier transporter and UDP glucuronosyltransferases in dogs with aggressive cutaneous mast cell tumours. Vet $J$ 212:36-43.

Giantin M, Granato A, Baratto C, Marconato L, Vascellari M, Morello EM, Vercelli A, Mutinelli F, and Dacasto M (2014) Global gene expression analysis of canine cutaneous mast cell tumor: could molecular profiling be useful for subtype classification and prognostication? PLoS One 9:e95481.

Gil da Costa RM (2015) C-kit as a prognostic and therapeutic marker in canine cutaneous mast cell tumours: from laboratory to clinic. Vet $J$ 205:5-10.

Hadzijusufovic E, Peter B, Herrmann H, Rülicke T, Cerny-Reiterer S, Schuch K Kenner L, Thaiwong T, Yuzbasiyan-Gurkan V, Pickl WF, et al. (2012) NI-1: a novel canine mastocytoma model for studying drug resistance and IgER-dependent mast cell activation. Allergy 67:858-868

Halsey CHC, Gustafson DL, Rose BJ, Wolf-Ringwall A, Burnett RC, Duval DL, Avery AC, and Thamm DH (2014) Development of an in vitro model of acquired resistance to toceranib phosphate (Palladia $\left.{ }^{\circledR}\right)$ in canine mast cell tumor. BMC Vet Res 10:105-117.

Hasan TN, B LG, Shafi G, Al-Hazzani AA, and Alshatwi AA (2011) Anti-proliferative effects of organic extracts from root bark of Juglans Regia L. (RBJR) on MDA-MB231 human breast cancer cells: role of Bcl-2/Bax, caspases and Tp53. Asian Pac J Cancer Prev 12:525-530.

Huang L, Zhang T, Li S, Duan J, Ye F, Li H, She Z, Gao G, and Yang X (2014) Anthraquinone G503 induces apoptosis in gastric cancer cells through the mitochondrial pathway. PLoS One 9:e108286.

Huang Q, Lu G, Shen HM, Chung MCM, and Ong CN (2007) Anti-cancer properties of anthraquinones from rhubarb. Med Res Rev 27:609-630.

Huppert JL and Balasubramanian S (2007) G-quadruplexes in promoters throughout the human genome. Nucleic Acids Res 35:406-413.

Kang SG and Henderson E (2002) Identification of non-telomeric G4-DNA binding proteins in human, E. coli, yeast, and Arabidopsis. Mol Cells 14:404-410.

Koirala D, Ghimire C, Bohrer C, Sannohe Y, Sugiyama H, and Mao H (2013) Longloop G-quadruplexes are misfolded population minorities with fast transition kinetics in human telomeric sequences. J Am Chem Soc 135:2235-2241.

Kota S, Dhamodharan V, Pradeepkumar PI, and Misra HS (2015) G-quadruplex forming structural motifs in the genome of Deinococcus radiodurans and their regulatory roles in promoter functions. Appl Microbiol Biotechnol 99:9761-9769.

Lipps HJ and Rhodes D (2009) G-quadruplex structures: in vivo evidence and function. Trends Cell Biol 19:414-422.

Livak KJ and Schmittgen TD (2001) Analysis of relative gene expression data using realtime quantitative PCR and the 2(-Delta Delta C(T)) method. Methods 25:402-408.

London CA, Malpas PB, Wood-Follis SL, Boucher JF, Rusk AW, Rosenberg MP, Henry CJ, Mitchener KL, Klein MK, Hintermeister JG, et al. (2009) Multi-center, placebo-controlled, double-blind, randomized study of oral toceranib phosphate (SU11654), a receptor tyrosine kinase inhibitor, for the treatment of dogs with recurrent (either local or distant) mast cell tumor following surgical excision. Clin Cancer Res 15:3856-3865.

Maizels N and Gray LT (2013) The G4 genome. PLoS Genet 9:e1003468.

McLuckie KI, Waller ZA, Sanders DA, Alves D, Rodriguez R, Dash J, McKenzie GJ, Venkitaraman AR, and Balasubramanian S (2011) G-quadruplex-binding benzo[a]phenoxazines down-regulate c-KIT expression in human gastric carcinoma cells. J Am Chem Soc 133:2658-2663.

Milovancev M, Helfand SC, Marley K, Goodall CP, Löhr CV, and Bracha S (2016) Antiproliferative effects of masitinib and imatinib against canine oral fibrosarcoma in vitro. BMC Vet Res 12:85-98.

Patel DJ, Phan AT, and Kuryavyi V (2007) Human telomere, oncogenic promoter and 5'-UTR G-quadruplexes: diverse higher order DNA and RNA targets for cancer therapeutics. Nucleic Acids Res 35:7429-7455.

Rachwal PA and Fox KR (2007) Quadruplex melting. Methods 43:291-301.

Raiber EA, Kranaster R, Lam E, Nikan M, and Balasubramanian S (2012) A noncanonical DNA structure is a binding motif for the transcription factor SP1 in vitro. Nucleic Acids Res 40:1499-1508.

Rankin S, Reszka AP, Huppert J, Zloh M, Parkinson GN, Todd AK, Ladame S, Balasubramanian S, and Neidle S (2005) Putative DNA quadruplex formation within the human c-kit oncogene. J Am Chem Soc 127:10584-10589.

Rawal P, Kummarasetti VB, Ravindran J, Kumar N, Halder K, Sharma R, Mukerji M, Das SK, and Chowdhury S (2006) Genome-wide prediction of G4 DNA as regulatory motifs: role in Escherichia coli global regulation. Genome Res 16: 644-655.

Rhodes D and Lipps HJ (2015) G-quadruplexes and their regulatory roles in biology. Nucleic Acids Res 43:8627-8637.

Rossi G, Bertani C, Mari S, Marini C, Renzoni G, Ogilvie G, and Magi GE (2013) Ex vivo evaluation of imatinib mesylate for induction of cell death on canine neoplastic mast cells with mutations in c-Kit exon 11 via apoptosis. Vet Res Commun 37: 101-108.

Siddiqui-Jain A, Grand CL, Bearss DJ, and Hurley LH (2002) Direct evidence for a G-quadruplex in a promoter region and its targeting with a small molecule to repress c-MYC transcription. Proc Natl Acad Sci USA 99:11593-11598.

Teng FY, Hou XM, Fan SH, Rety S, Dou SX, and Xi XG (2017) Escherichia coli DNA polymerase I can disrupt G-quadruplex structures during DNA replication. FEBS $J$ 284:4051-4065.

Tian M, Zhang X, Li Y, Ju Y, Xiang J, Zhao C, and Tang Y (2010) Inducement of G-quadruplex DNA forming and down-regulation of oncogene c-myc by bile acidamino acid conjugate-BAA. Nucleosides Nucleotides Nucleic Acids 29:190-199.

van de Ven R, Verbrugge SE, Reurs AW, Bontkes HJ, Hooijberg E, Jansen G, Scheper RJ, Scheffer GL, and de Gruijl TD (2011) High susceptibility of c-KIT ${ }^{+} \mathrm{CD} 34^{+}$ precursors to prolonged doxorubicin exposure interferes with Langerhans cell differentiation in a human cell line model. Cancer Immunol Immunother 60: 943-951.

Verma A, Halder K, Halder R, Yadav VK, Rawal P, Thakur RK, Mohd F, Sharma A, and Chowdhury S (2008) Genome-wide computational and expression analyses reveal G-quadruplex DNA motifs as conserved cis-regulatory elements in human and related species. $J$ Med Chem 51:5641-5649.

Wang L and Wei C (2013) Spectroscopic and biological studies of phenanthroline compounds: selective recognition of gene-promoter G-quadruplex DNAs preferred over duplex DNA. Chem Biodivers 10:1154-1164.

Yamada O, Kobayashi M, Sugisaki O, Ishii N, Ito K, Kuroki S, Sasaki Y, Isotani M, Ono K, Washizu T, et al. (2011) Imatinib elicited a favorable response in a dog with a mast cell tumor carrying a c-kit c.1523A $>$ T mutation via suppression of constitutive KIT activation. Vet Immunol Immunopathol 142:101-106.

Zhao Y, Du Z, and Li N (2007) Extensive selection for the enrichment of G4 DNA motifs in transcriptional regulatory regions of warm blooded animals. FEBS Lett 581:1951-1956.

Zorzan E, Da Ros S, Musetti C, Shahidian LZ, Coelho NFR, Bonsembiante F, Létard S, Gelain ME, Palumbo M, Dubreuil P, et al. (2016) Screening of candidate G-quadruplex ligands for the human c-KIT promotorial region and their effects in multiple in-vitro models. Oncotarget 7:21658-21675.

Address correspondence to: Dr. Mauro Dacasto, Department of Comparative Biomedicine and Food Science, Division of Veterinary Pharmacology and Toxicology, University of Padua, viale dell'Università 16, Agripolis Legnaro, I-35020 Padua, Italy. E-mail: mauro.dacasto@unipd.it; or Dr. Claudia Sissi, Department of Pharmaceutical and Pharmacological Sciences, University of Padua, via Marzolo 5, I-35131 Padua, Italy. E-mail: claudia.sissi@unipd.it 